\title{
LEVANTAMENTO DAS PERSPECTIVAS DOS ATORES SOCIAIS DA FEIRA DO PESCADO DE SANTARÉM, PARÁ, BRASIL, ACERCA DO PERÍODO DE DEFESO
}

\author{
Devaneris Viegas Tavares (D) $\triangle$ \\ Universidade da Amazônia I Santarém - PA - Brasil
}

Tiago Henrique Rodrigues Siebert $\triangle$

Universidade da Amazônia I Santarém - PA - Brasil

Paloma Rodrigues Siebert (ID $ه$

Instituto Federal do Pará I Santarém - PA - Brasil 


\section{RESUMO}

Este estudo objetivou identificar a compreensão de atores sociais da Feira do Pescado, em Santarém, Pará, Brasil, acerca da política de seguro-desemprego do pescador artesanal. Para tanto, realizou-se pesquisa documental e de campo, a fim de construir conhecimento acerca da atuação das entidades representativas e dos associados à colônia de pescadores do município de Santarém. Para a coleta de dados, foram aplicados oitenta questionários com questões abertas e fechadas. Os resultados foram tabelados, bem como elaborou-se mapas conceituais, para melhor visualização das respostas obtidas. Os dados permitiram inferir que a pesca artesanal em Santarém enfrenta desafios diversos nas áreas social, econômica e ambiental, de modo a atender à demanda crescente da comunidade, ao mesmo tempo em que há inegável necessidade do estabelecimento de ações que busquem a preservação ambiental das espécies de pescado.

Palavras-chave: período de defeso; pesca; concepções; atores sociais

\section{SURVEY ON THE PERSPECTIVES OF THE SOCIAL ACTORS OF THE FISH FAIR OF SANTARÉM, PARÁ, BRAZIL, ABOUT THE OFF SEASON}

This study aimed to identify the understanding of social actors of the Fish Fair in Santarém, Pará, Brazil, about the unemployment insurance policy of the artisanal fisherman..In order to do so, we performed documentary and field research in order to build knowledge about the performance of the representative entities and those associated with the fishermen's colony of the municipality of Santarém. For the data collection, eighty questionnaires with open and closed questions were applied. The results were tabulated, as well as conceptual maps were elaborated aiming at greater visualization of the obtained answers. The data allowed us to infer that artisanal fishing in Santarém faces different challenges in the social, economic and environmental areas, in order to meet the increasing demand of the community, while there is an undeniable need to establish actions aimed at the environmental preservation of the species of fish.

Keywords: $\bigcirc$ ff season; fishing;

\section{LEVANTAMIENTO DE PERSPECTIVAS DE LOS ACTORES SOCIALES DE LA FERIA DEL PESCADO DE SANTARÉM, PARÁ, BRASIL, ACERCA DE LA VEDA}

\section{RESUMEN}

Este estudio tuvo por objeto identificar la comprensión de actores sociales de la Feria del Pescado en Santarém, Pará, Brasil, acerca de la Política del Seguro Desempleo del Pescador Artesanal. Para ello, se realizó investigación documental y de campo, a fin de construir conocimiento acerca de la actuación de las entidades representativas y los asociados a la colonia de pescadores del municipio de Santarém. Para la recolección de datos se aplicaron ochenta cuestionarios con preguntas abiertas y cerradas. Los resultados fueron tabulados, también se elaboraron mapas conceptuales para una mejor visualización de las respuestas obtenidas. Los datos permitieron inferir que la pesca artesanal en Santarém enfrenta desafíos diversos en las áreas social, económica y ambiental, para atender la creciente demanda de la comunidad; al tiempo que hay una innegable necesidad de acciones destinadas a la preservación ambiental de las especies de peces.

Palabras clave: veda; pesca; concepciones: actores sociales 


\section{INTRODUÇÃO}

A pesca é uma das mais antigas atividades praticadas no mundo. No Brasil, a sua evolução é marcada por diferentes etapas, que acompanham o desenvolvimento do país. Assim sendo, ao longo do século XX, destaca-se a presença do pescador artesanal como personagem central desta atividade. A política brasileira de regulamentação da atividade pesqueira preocupou-se, durante muito tempo, com a criação de órgãos para regulamentar a extração do pescado, destacando a criação da Superintendência para o Desenvolvimento da Pesca (SUDEPE), a partir da década de 1960, quando a atividade pesqueira tomou maior impulso, mas pouco se preocupou em diagnosticar e ampliar o estoque de pescado nacional, fato que somente se concretizou a partir de 1989 , com a criação do Instituto Brasileiro do Meio Ambiente e dos Recursos Naturais Renováveis (IBAMA). As regulamentações voltadas para o ordenamento pesqueiro começaram a fazer parte ativamente da política nacional para tal atividade a partir da década de 1970, porém, tomaram maior dimensão a partir da segunda metade dos anos 1980, em um contexto de maior preocupação com a conservação dos recursos naturais renováveis (Maia 2009).

Segundo Mathis (2001), por falta de legislações específicas, tornam-se ineficientes as ações de preservação ambiental e de políticas preservacionistas desenvolvidas pelo poder público. Conforme o autor, as leis ordinárias, em vigor na época de sua pesquisa, voltadas à punição de infratores do meio ambiente são, em sua maioria, inócuas e obsoletas, seja por falta de previsão para determinados comportamentos danosos, seja por estabelecerem penas ora demasiadamente severas ora leves demais. Os instrumentos legais - como o Código de Pesca, no caso da atividade pesqueira - tratam da questão ambiental de forma pontual e dissociada, não considerando o meio ambiente como um todo.

Surge, nesse contexto, com iniciativa do IBAMA, o Projeto de Lei de Crimes Ambientais, que iniciou seu trâmite nas instâncias legais em 1991. Esta lei foi sancionada em 1998 e atualmente é conhecida como "Lei da vida: Lei dos crimes ambientais" (Lei n. 9.605, de 12 de fevereiro de 1998) (IBAMA 2014).

Diante das dificuldades enfrentadas pelo setor pesqueiro/artesanal, com sucessivas diminuições na produção, atreladas à necessidade de manejo das espécies da pesca marinha e de águas continentais para garantir a sustentabilidade do recurso, a partir de 2003, o governo federal criou a política do Seguro-Desemprego do Pescador Artesanal (SDPA), conhecida também como "seguro-defeso". Essa política tem como finalidade garantir a renda do pescador artesanal durante o período da proibição da pesca e, com isso, contribuir com a reprodução das espécies. O seguro-defeso situa-se na confluência das políticas sociais e ambientais definidas após a Constituição Federal de 1988, no Brasil. Trata-se de uma política pública que ampara os pescadores artesanais, os quais são impedidos de subsistir com seu trabalho durante certo período do ano - segundo a lei, no momento da desova de determinadas espécies -, oferecendo proteção e possibilidade de repovoamento das populações marinhas, fluviais e lacustres que integram o ecossistema brasileiro (Brasil 2003).

A Comissão das Comunidades Europeias, realizada em 2001, relatou que todas as atividades de 
pesca causam impactos nos ecossistemas aquáticos e depredam o ambiente, sendo que, frequentemente, não se tem noção da gravidade desse impacto e do tempo necessário para recomposição dos danos. Em função disso, torna-se necessário que sejam tomadas medidas normativas para evitar o colapso das economias pesqueiras (Peres et al. 2001), objetivando a proteção das espécies em épocas de reprodução ou de recrutamento (Vasques \& Couto 2011).

Durante a vigência do período de defeso, o profissional da pesca fica impossibilitado de praticar a atividade sobre as espécies protegidas. Em contrapartida, o pescador recebe, nesse período, o seguro desemprego, que visa auxiliar economicamente os dependentes diretos dessa atividade, permitindo a redução do esforço de pesca sobre os estoques naturais, que estão recrutando (Pieve et al. 2008). No entanto, notase que, mesmo contemplados com este benefício, alguns pescadores continuam exercendo a atividade ilegalmente e comercializando o pescado (Moreira et al. 2009).

Na região amazônica, Vidal et al. (2015) discutem os aspectos complexos do setor da pesca continental:

A gestão da pesca em água doce muitas vezes é extremamente difícil devido à natureza dispersa da pesca, ao grande número de pessoas envolvidas e à distância dos grandes centros urbanos. Como resultado, os regulamentos de pesca são poucas vezes aplicados e, mesmo quando aplicados, o seu sucesso também pode ser questionável, porque normalmente são estabelecidos pelas autoridades do governo central e não atendem às necessidades de cada um dos corpos d'água e às populações de pescadores. Além disso, os fatores de mudança e produtividade em muitas populações de peixe surgem de fora da pesca, geralmente sob a forma de impactos ambientais decorrentes de outros usuários ou atividades de exploração dos recursos aquáticos (Vidal et al. 2015:58).

Dessa forma, por apresentar uma gestão ineficiente, sem o estabelecimento de efetivas políticas públicas para a promoção do desenvolvimento sustentável dos recursos naturais, com manejo inadequado, falhas no monitoramento e no controle e deficiências nas estratégias específicas para conservação dos ecossistemas de várzea na região central da bacia amazônica, foi criado, no início da década de 2000, o Projeto Manejo dos Recursos Naturais da Várzea (ProVárzea) (IBAMA 2002; Santos 2005; SilvaForsberg et al. 2006; Vidal et al. 2015).

De acordo com Vidal et al. (2015), o ProVárzea investiu cerca de $\mathrm{R} \$ 8.928 .834,34 \mathrm{em} 25$ projetos, apoiados no período de janeiro de 2002 a setembro de 2007. A maior parte deste recurso, segundo os autores, foi destinada à capacitação, ao monitoramento, à conservação e à comercialização da produção, sendo beneficiadas cerca de 115.486 pessoas em 39 municípios dos estados do Amazonas e do Pará. Foram manejados aproximadamente 100.000 hectares de ecossistemas terrestres e aquáticos, com uma parcela significativa de áreas aquáticas regidas por acordos de pesca, alguns dos quais foram formalizados por meio de Instruções Normativas do IBAMA, elaboradas e/ou reeditadas 
sob a influência das ações dos projetos. O município de Santarém foi beneficiado com pelo menos nove dessas Instruções Normativas, regulamentando a pesca na região.

Os principais autores que fazem uso dos recursos da região de várzea são ribeirinhos, fazendeiros e pescadores comerciais. Os ribeirinhos são moradores das comunidades de várzeas, podem apresentar diversidade de fonte econômica, como criação de animais, agricultura e extrativismos, mas, em geral, a atividade principal deles é a pesca artesanal. Nesse sentido, estes atores são os criadores dos acordos de pesca e, portanto, são os que mais se beneficiam com o seu estabelecimento. Em relação aos fazendeiros, pode-se dizer que são criadores de gado e utilizam as várzeas no período de seca. Em geral, eles não são diretamente prejudicados com os acordos de pesca, porque possuem pouca ligação com esta atividade. Quem, no entanto, é prejudicado por esses acordos são os pescadores comerciais, provenientes das áreas urbanas; eles podem ser capitalizados com barcos e equipamentos mais sofisticados, com capacidade para realizar deslocamentos por longas distâncias, ou pouco capitalizados, praticando a pesca apenas em lagos e várzeas próximas à área urbana. $O$ fato de os pescadores urbanos serem considerados "invasores" de lagos comunitários é fonte de constantes conflitos de pesca (Castro \& Mcgrath 2001).

Desde o início do ProVárzea, uma crescente quantidade de acordos de pesca na Amazônia passou a ser observada. O fato de criar um acordo de pesca, contudo, não garante o êxito no manejo comunitário. As regras estabelecidas devem atender às demandas de todo sistema comunitário, contemplando, assim, os aspectos ecológicos, sociais e econômicos envolvidos. De acordo com Castro \& Mcgrath (2001), a elaboração de acordos de pesca na região amazônica evidencia que os grupos usuários das áreas de pesca são agentes ativos que se relacionam com o recurso, entre si, e com o sistema externo, e respondem conforme os padrões de oportunidades e de limites ambientais, articulando as características ecológicas, sociais e econômicas. Como o ambiente de várzea é complexo, heterogêneo e dinâmico em todas estas dimensões, os acordos de pesca devem ser observados como uma instituição igualmente complexa, com resultados variados, segundo as características ecológicas e sociais de cada caso.

A região de Santarém apresenta diversas comunidades ribeirinhas, que vivem às margens de rios e lagos. Nesses locais, observam-se muitos acordos de pesca objetivando a construção de instrumentos comunitários para gestão sustentável dos recursos pesqueiros. Como exemplo, podemos destacar a comunidade Ilha de São Miguel, na região de várzea do rio Amazonas. Nela, foi elaborado, no ano de 1985, o acordo de pesca que é mantido até os dias atuais, o qual restringiu a permissão de pesca na ilha apenas aos moradores da área, bem como proibiu definitivamente o uso de malhadeiras. Outras ações foram consolidadas pelos moradores, tais como o manejo e o controle da comercialização do pirarucu (Arapaima gigas), bem como a fiscalização dos lagos pelos pescadores, evidenciando uma alternativa promissora para uma gestão da pesca por meio do uso racional dos recursos pesqueiros na comunidade (Ferreira \& Silva 2017). 
Segundo Silva \& Ferreira (2018), nas microrregiões de Santarém, entre 1990 a 2004, foram observados 42 acordos de pesca para as regiões do Tapará, Urucurituba, Ituqui, Lago Grande, Arapixuna, Maicá, Aritapera, além de Juá e Área Verde. Dessa forma, esses acordos, em consonância com as políticas públicas voltadas a atingir populações ribeirinhas, apontam para um processo social dinâmico, no qual ribeirinhos e governo elaboraram agendas a partir de necessidades coletivas.

Neste contexto, e entendendo a importância da atividade pesqueira na região do baixo Amazonas, bem como a relevância de políticas públicas voltadas para tal atividade, este artigo buscou identificar as perspectivas de comerciantes, consumidores e pescadores artesanais acerca da aplicabilidade da política do Seguro-Desemprego do Pescador Artesanal na cidade de Santarém, Pará, Brasil. Trata-se de um levantamento cujos resultados poderão servir de subsídios para o planejamento de políticas públicas e para elaboração de projetos voltados à área de educação ambiental pesqueira.

Cabe destacar que a cidade de Santarém está localizada na confluência dos rios Amazonas e Tapajós, na região oeste do estado do Pará, no Norte do Brasil, na América do Sul. O município ocupa área de $22.887 \mathrm{~km}^{2}$ e possui população de 296.302 habitantes. Foi fundado em 22 de junho de 1661, pelo padre jesuíta, nascido em Luxemburgo, João Felipe Bettendorf, e elevado à categoria de cidade no dia 24 de outubro de 1848 (IBGE 2017).

A zona rural do município de Santarém está dividida em sub-regiões: várzeas (regiões ribeirinhas e de várzeas ao longo do rio Amazonas, no território do município); rios Tapajós e Arapiuns (terras envolvidas pelas áreas ribeirinhas desses rios e respectivas zonas de influência); Lago Grande (regiões de várzeas e terra firme que compõem a área entre as margens direita do rio Amazonas e esquerda do rio Arapiuns); Planalto (áreas de terra firme, entre as bacias dos rios Curuá-Una e Tapajós) (IBGE 2017).

Economicamente, essas sub-regiões envolvem manifestações culturais, produções agrícolas diversas e a pesca artesanal, cujos atores são os pequenos produtores do município de Santarém. Eles comercializam seus produtos agrícolas e pesqueiros, motivados pelas demandas sociais e culturais. O pescado na região é abundante: são, aproximadamente, 2.300 espécies de peixes que constituem a fauna da Amazônia, sendo que cerca de 100 delas são exploradas comercialmente ou destinadas ao consumo familiar. Em Santarém, observa-se que uma parcela significativa do pescado que desembarca na cidade é composta por somente dez espécies de peixes (Cerdeira et al. 1997), as quais têm como principal ponto de desembarque o local tradicionalmente denominado pelos pescadores e pela população como Feira do Pescado, na orla da cidade.

\section{METODOLOGIA}

Este estudo apresenta enfoque quantitativo e qualitativo, na busca por compreender as perspectivas de atores sociais da Feira do Pescado, em Santarém, Pará, acerca da aplicabilidade da política do seguro-desemprego do pescador artesanal. O estudo qualitativo foi escolhido, pois, segundo Teixeira (2006:137), "com o enfoque qualitativo o pesquisador procura reduzir a distância entre a teoria e os dados, entre o contexto 
e a ação, usando a lógica da análise fenomenológica, isto é, da compreensão dos fenômenos pela sua descrição e interpretação”.

Kauark et al. (2010) apresentam, ainda, a definição de pesquisa qualitativa:

A interpretação dos fenômenos e a
atribuição de significados são básicas
no processo de pesquisa qualitativa.
Não requer o uso de métodos e técnicas
estatísticas. O ambiente natural é a
fonte direta para coleta de dados e o
pesquisador é o instrumento-chave. É
descritiva. Os pesquisadores tendem a
analisar seus dados indutivamente. O
processo e seu significado são os focos
principais de abordagem (Kauark et
al. 2010:26).

Já as categorias de análise da pesquisa quantitativa, de acordo com Stake (1983), são: perceber o fenômeno; isolar casos; observar sequências, testemunhos, contextos; selecionar casos; observar, entrevistar, registrar; determinar padrões, selecionar e classificar; triangular, validar, interpretar; fazer estudos de casos ou relatórios; produzir: compreender com ênfase em generalidades; realçar valores, compreensão e atitudes.

Segundo Grácio \& Garrutti (2005), atualmente, faz-se necessária a superação da dicotomia das abordagens qualitativa e quantitativa. Além disso, é preciso aproximar a área da Educação com a quantificação, pois isso possibilita uma concepção mais completa dos problemas que encontramos em nossa realidade. De acordo com os autores, "as quantificações fortalecem os argumentos e constituem indicadores importantes para análises qualitativas" (Grácio \& Garrutti 2005:119). Sendo assim:

[...] destacamos a relevância da complementaridade entre as tendências que orientam as atuais pesquisas, para a resolução de problemas de diversas naturezas. Nesse sentido, no presente trabalho, consideramos que também no âmbito educacional deve haver a complementaridade entre os enfoques metodológicos para que se possa alcançar resultados de pesquisa mais amplos e globais (Grácio \& Garrutti 2005:120).

Gil (1999:35) também expõe que “os procedimentos estatísticos fornecem considerável reforço às conclusões obtidas”, uma vez que apresentam razoáveis graus de precisão, tornandoos bastante aceitos entre os pesquisadores.

Participaram do presente estudo 80 indivíduos, divididos entre pescadores (20 sujeitos), comerciantes (30 sujeitos) e consumidores (30 sujeitos), e os dados foram coletados na Feira do Pescado, em Santarém, Pará. Cabe destacar que, segundo as informações oficiais concedidas por dirigentes da Colônia de Pescadores Z-20, entidade responsável pela administração do espaço, estão cadastrados 119 trabalhadores, distribuídos entre pescadores/vendedores de pescado, verdureiros, vendedores de lanche e carregadores.

$\mathrm{Na}$ fase da pesquisa exploratória, os sujeitos foram convidados a participar da pesquisa. Após assinarem um Termo de Consentimento Livre e Esclarecido, foi aplicado um questionário, com perguntas abertas e fechadas, a 50 trabalhadores da Feira do Pescado, entre eles 20 são pescadores 
e 30 são comerciantes, o que corresponde a 42,01\% de um público de 119 trabalhadores do local. Além disso, participaram da pesquisa 30 consumidores que frequentam o espaço. O questionário completo pode ser visualizado no Apêndice 1. Cabe ressaltar que este documento foi preenchido pelos pesquisadores de acordo com as respostas emitidas pelos sujeitos participantes do estudo, uma vez que a maioria deles encontrava-se manuseando pescado no momento da abordagem.

Os dados obtidos por meio das perguntas fechadas foram tabulados e quantificados, compondo tabelas, já as respostas obtidas por meio das perguntas abertas foram organizadas em categorias de análise. Para Bardin (1977), a categorização pode ser definida como:

[...] uma operação de classificação de elementos constitutivos de um conjunto, por diferenciação e, seguidamente, por reagrupamento segundo o gênero, com critérios previamente definidos. As categorias são rubricas ou classes, as quais reúnem um grupo de elementos sob um título genérico, agrupamento esse efetuado em razão dos caracteres comuns destes elementos. A categorização tem como primeiro objetivo fornecer, por condensação, uma representação simplificada dos dados brutos (Bardin 1977:117).

De acordo com Lüdke \& André (1986), a tarefa de análise implica a organização do material obtido e o estabelecimento de relações entre esse material, procurando identificar padrões e tendências relevantes. Organizamos as respostas dos sujeitos da pesquisa em três categorias de análise: 1) importância da Portaria de Defeso; 2) problemas identificados por pescadores, consumidores e comerciantes; e 3) intervenção do Estado como mecanismo de controle.

\section{RESULTADOS E DISCUSSÃO}

No Pará, o período de defeso inicia no dia 15 de novembro e termina no dia 15 de março. O município de Santarém destaca-se como um dos principais polos de produção pesqueira do estado, diante das potencialidades naturais das várzeas existentes em torno de toda extensão do rio Amazonas, onde o município faz suas confrontações geográficas. Entretanto, a atividade pesqueira é carente de estudos e pesquisas socioeconômicas que possibilitem maior desenvolvimento da região e, por consequência, gerem excedentes comercializáveis para melhorar a qualidade de vida das populações que dependem da pesca (IBAMA 2007).

Em Santarém, as espécies que estão protegidas são o pacu (Myleus spp. e Mylossoma spp.), a jatuarana (Brycon spp.), a pirapitinga (Piaractus brachypomus), o aracu (Schizodon spp.), a fura-calça (Pimelodina flavipinnis), o mapará (Hypophthalmus edentatus), o curimatá (Prochilodus nigricans) e a branquinha (Curimata amazonica, $C$. inorata) (IBAMA 2007). A pesca do tambaqui (Colossoma macropomum) é proibida do dia $1^{\circ}$ de outubro até 31 de dezembro (IBAMA 2005); o acari (Liposarcus pardalis) entra no período de defeso entre o dia $1^{\circ}$ de dezembro a 31 de maio; e o pirarucu (Arapaima gigas), entre $1^{\circ}$ de dezembro e 31 de maio (IBAMA 2004). Nos tópicos que seguem, serão apresentadas as sistematizações e a discussão dos resultados dos questionários. A apresentação dos dados está 
dividida entre as respostas emitidas às questões fechadas e abertas.

\subsection{ANÁLISE DAS RESPOSTAS EMITIDAS ÀS QUESTÕES FECHADAS}

As Tabelas de 1 a 3 tratam de informações fornecidas pelos atores sociais que são formados por pescadores, comerciantes e consumidores da Feira do Pescado, em Santarém, Pará, sobre a política do seguro-desemprego do pescador artesanal.

A Tabela 1 permite-nos inferir que há um conhecimento significativo por parte dos pescadores acerca do que é o período de defeso, bem como de sua importância para muitas espécies de peixes comerciais. Essa inferência é decorrente da observação de que $100 \%$ dos trabalhadores que fornecem peixe na Feira do Pescado, em Santarém, Pará, são favoráveis a este período e 95\% têm conhecimento das normas que regulam o evento marcado pela desova das espécies. Dos 20 pescadores que participaram desta pesquisa, apenas um mencionou não conhecer o período em questão. É válido refletir que esta resposta pode estar relacionada ao fato de o entrevistado não conhecer as normas que regulam esta política pública, mas também por não compreender a pergunta que foi realizada ou, ainda, por não possuir conhecimento aprofundado acerca do tema, optando por assinalar que não apresentava entendimento sobre o assunto. Destaca-se, ainda, que todos os pescadores afirmaram concordar com a existência de normas para garantir a sobrevivência das espécies, ou seja, para o grupo entrevistado, o período de defeso é muito importante.

Sobre as espécies liberadas ou do estoque, $100 \%$ dos pesquisados comercializam ou comercializaram pescado nesse período. Optamos por não perguntar se este material se refere a pescado proibido, pois, uma vez que se trata de uma atividade ilegal, o questionamento poderia constranger o respondente. No entanto, inferimos que provavelmente as espécies comercializadas no período em questão estariam protegidas pelo defeso, dado que são as mais rentáveis e consumidas. Portanto, não poderia haver essa comercialização. Aqui, nota-se um dado interessante: os mesmos pescadores que afirmam ser favoráveis à existência

Tabela 1 - Respostas dos pescadores da Feira do Pescado ao questionário sobre o período de defeso, aplicado entre 8 a 14 de setembro de 2017, em Santarém, Pará.

\begin{tabular}{l|l|l|l|l}
\hline Pescador & Não & $\%$ & Sim & $\%$ \\
\hline Favorável ao período de defeso & - & - & 20 & 100 \\
\hline Tem conhecimento sobre o período de defeso & 1 & 5 & 19 & 95 \\
\hline Comercializa ou já comercializou pescado no período de defeso & - & - & 20 & 100 \\
\hline Acredita que ainda haveria peixe em abundância sem o período de defeso & 20 & 100 & - & - \\
\hline Considera importante o período de defeso & - & - & 20 & 100 \\
\hline
\end{tabular}


do defeso são os que possivelmente comercializam ou já comercializaram pescado protegido por esta política pública. Essa aparente incoerência pode ser explicada por graves falhas que ocorrem na aplicação de tal política, as quais podem vir a prejudicar os pescadores e suas famílias. Este dado fica mais evidente ao analisarmos as respostas dadas às perguntas abertas, expostas e discutidas no tópico seguinte.

A análise das respostas dos comerciantes às perguntas fechadas, sistematizadas na Tabela 2, permite-nos deduzir que, de modo geral, o grupo de sujeitos participantes da pesquisa também apresenta conhecimentos sobre a política do período de defeso. No entanto, cabe destacar que, comparado ao grupo dos pescadores, o índice referente aos comerciantes é menor, uma vez que um número considerável de entrevistados (17\%) afirmou ser contra tal política, apesar de apenas um participante entre eles ter informado não possuir conhecimento acerca do tema.

Outro dado relevante extraído desta pesquisa é que uma parcela significativa dos comerciantes que participaram deste estudo (40\%) afirmou comercializar ou já ter comercializado pescado durante o período de fechamento da pesca. Novamente, enfatizamos que não necessariamente o pescado em questão se encontra protegido, mas, dado que as espécies que entram no período são as mais rentáveis comercialmente, há uma possibilidade elevada de tratar-se destes animais. É válido salientar que, apesar de este número ser significativamente menor do que o de pescadores que afirmaram realizar tal atividade (no caso, 100\%), ainda assim trata-se de uma porcentagem elevada.

A prática de comercializar pescado proibido durante o período estudado vai ao encontro das respostas dadas pelos comerciantes, ao serem questionados se ainda haveria peixe em abundância sem esta política pública. Um elevado número de respondentes (30\%) afirmou que sim, ou seja, para este expressivo número de pessoas ainda haveria peixe com fartura, mesmo sem a Portaria do Defeso. Em outras palavras, o desconhecimento dos indivíduos acerca da biologia das espécies dulcícolas, seus modos de vida e suas particularidades reprodutivas pode ser responsável pela perpetuação da falsa concepção de que os recursos biológicos são infinitos, culminando, então, na despreocupação em comercializar pescado protegido durante o defeso.

Tabela 2 - Respostas dos comerciantes da Feira do Pescado ao questionário sobre o período de defeso, aplicado entre 8 a 14 de setembro de 2017, em Santarém, Pará.

\begin{tabular}{l|l|l|l|l}
\hline Comerciante & Não & $\%$ & Sim & $\%$ \\
\hline Favorável ao período de defeso & 5 & 17 & 25 & 83 \\
\hline Tem conhecimento sobre o período de defeso & 1 & 3 & 29 & 97 \\
\hline Comercializa ou já comercializou pescado no período de defeso & 18 & 60 & 12 & 40 \\
\hline Acredita que ainda haveria peixe em abundância sem o período de defeso & 21 & 70 & 9 & 30 \\
\hline Considera importante o período de defeso & 5 & 17 & 25 & 83 \\
\hline
\end{tabular}


A Tabela 3 indica que a maioria expressiva de consumidores que participaram desta pesquisa $(90 \%)$ é favorável e afirmou apresentar conhecimentos (87\%) acerca da política do período de defeso. Destaca-se, ainda, que a quase totalidade dos respondentes na qualidade de consumidores $(97 \%)$ afirmou considerar importante esta política pública.

Um dado relevante a ser mencionado é que uma porcentagem considerável dos consumidores entrevistados (17\%) afirmou que ainda haveria peixe em abundância, mesmo sem a existência do período de defeso. Ou seja, é nítido que alguns respondentes não compreendem bem o tema, apesar de acreditarem possuir conhecimentos suficientes neste assunto, uma vez que, como já afirmado, o período de fechamento da pesca existe exatamente para que as espécies protegidas possam se recuperar enquanto populações. Sem a existência desta política pública, a desova e a maturidade das espécies juvenis seriam prejudicadas.

Outro dado importante dessa parte das entrevistas refere-se ao consumo dos produtos proibidos no defeso. Um número considerável de consumidores pesquisados (44\%) afirmou que consome ou já consumiu pescado proibido durante o período de fechamento da pesca. Nesse caso, a pergunta foi direta (ou seja, diferentemente dos outros casos, questionou-se sobre o consumo de pescado proibido), dado que não há sanções para consumidores de espécies proibidas, apenas para pescadores e comerciantes. Mais uma vez, é válido destacar que a ausência de conhecimentos acerca da importância do fechamento da pesca, bem como o pensamento individualista podem contribuir para que os consumidores não se preocupem com o tipo de pescado que estão comprando.

Por fim, outro dado sobre o qual é preciso refletir concerne ao fato de que a quase totalidade dos consumidores entrevistados (97\%) considera importante a existência do período em questão, mas uma porcentagem um pouco menor $(90 \%)$ defende a sua existência. Em outras palavras, um pequeno grupo de consumidores assume a importância da política de fechamento da pesca, ao mesmo tempo em que defende que esta deixe de existir. Essa aparente incoerência pode ser explicada pela escassez do pescado no mercado, bem como pelo aumento dos preços dos produtos durante a vigência do período.

Tabela 3 - Respostas dos consumidores da Feira do Pescado ao questionário sobre o período de defeso, aplicado entre 8 a 14 de setembro de 2017, em Santarém, Pará.

\begin{tabular}{l|l|l|l|l}
\hline Consumidor & Não & $\%$ & Sim & $\%$ \\
\hline Favorável ao período de defeso & 3 & 10 & 27 & 90 \\
\hline Tem conhecimento sobre o período de defeso & 4 & 13 & 26 & 87 \\
\hline Consome ou já consumiu pescado proibido no período do defeso & 17 & 57 & 13 & 43 \\
\hline Considera que ainda haveria peixe em abundância sem o período do defeso & 25 & 83 & 5 & 17 \\
\hline Considera importante o período de defeso & 1 & 3 & 29 & 97 \\
\hline
\end{tabular}




\subsection{ANÁLISE DAS RESPOSTAS EMITIDAS ÀS QUESTÕES ABERTAS}

Organizamos as respostas dos sujeitos da pesquisa em duas categorias de análise - 1) a importância da Portaria do Defeso; e 2) problemas identificados por pescadores, consumidores e comerciantes -, as quais serão apresentadas e discutidas nos tópicos que seguem. Cabe destacar que foram selecionadas as falas mais relevantes para representar cada categoria de análise.

Com relação às colocações dos colaboradores desta pesquisa, optamos por adotar os seguintes critérios: para a exposição das respostas às perguntas abertas, serão destacados o segmento do trabalhador, a numeração, que pode ir de 1 a 80, seguida da idade e do gênero, ou seja, as fontes serão expostas como no modelo: (Pescador: 1, 45-M). A numeração seguirá a seguinte sequência: pescadores - 1 a 20; consumidores - 21 a 50; e comerciantes - 51 a 80.

\subsubsection{CATEGORIA 1: A IMPORTÂNCIA DA PORTARIA DO DEFESO}

Todos os pescadores que trabalham na Feira do Pescado, em Santarém, Pará, e que participaram desta pesquisa afirmaram que o período de defeso é muito importante, pois preserva as espécies, respeita o momento da desova, assegurando o futuro das gerações, contribuindo com o crescimento das populações e, ainda, garantindo o descanso do pescador. Nesse período em que os peixes estão desovando, se forem capturados, a possibilidade de garantir às espécies as gerações futuras é mínima.

O período de defeso é importante. Caso contrário, os peixes poderiam ser extintos dos lagos. O defeso ajuda a preservar e manter as espécies para garantir o sustento das pessoas nos próximos anos. [...] Sem o defeso poderia até mesmo acabar com os peixes e a sobrevivência das pessoas se tornaria mais difícil (Pescador: 2, 56-M).

O defeso é importante, pois é o tempo em que os peixes estão desovando e por conta desse fenômeno da natureza eles se multiplicam no ano seguinte. O defeso só traz solução para a preservação das espécies. Sem o defeso se tornaria um caos, porque as espécies poderiam ser extintas da natureza, dificultando a pesca e a sobrevivência das pessoas (Pescador: 3, 42-M).

O defeso é importante para a preservação dos peixes que se encontram no período da desova. Não podemos capturar as espécies nesse período (Pescador: 13, 77-M).

O período é importante para o peixe reproduzir e a gente descansa um pouco nessa época (Pescador: 18, 43-M).

A concepção da importância desse momento, apresentada pelos pescadores, é compartilhada pela maioria dos comerciantes, mas não por todos, conforme pode ser observado nos fragmentos que seguem:

O defeso não é importante porque a nossa renda cai muito nessa época. Os clientes procuram peixe, mas não tem (Comerciante: 52, 31-M).

O período não é importante porque não temos peixes para atender nossos clientes e por isso fica mais caro (Comerciante: 56, 46-M). 
Operíodo de defeso não é importante, pois não temos variedade de peixe para oferecer aos clientes (Comerciante: 74, 58-F).

Os fragmentos extraídos para exemplificar a concepção dos comerciantes que discordam da importância desse período deixam claro que, na verdade, o que incomoda a estes indivíduos é a queda na renda familiar e a impossibilidade de atender aos seus clientes. Em outras palavras, não necessariamente essas pessoas desconsideram a importância do defeso em si, tampouco menosprezam o mérito desta prática, mas a perda individual gerada pela política mencionada acaba se sobressaindo em relação aos aspectos coletivo e ambiental.

A maioria dos consumidores participantes da pesquisa também compartilha da concepção dos pescadores e de grande parte dos comerciantes, ou seja, para eles o período é importante para assegurar a manutenção das espécies. Os fragmentos que seguem ilustram esta afirmação:

Esse período é importante para preservar os peixes por ocasião da desova e, com isso, garante-se a alimentação nos próximos anos (Consumidor: 23, 35-M).
Esse período é importante. Mesmo que o peixe fique mais caro, assegura a reprodução e o crescimento dos filhotes (Consumidor: 25, 52-M).

Outro beneficio apontado por um consumidor no que tange à aplicação da política do período de defeso diz respeito ao papel do Estado brasileiro no combate às desigualdades sociais, ao distribuir renda aos pescadores artesanais, especialmente do interior, por meio do pagamento do seguro-defeso: "Esse período éimportante porque o pessoal do interior recebe o seguro. Odefeso não traz problema algum. Só ajuda. Sem o defeso, imagino que estariam passando fome" (Consumidor: 33, 67-M). Entretanto, essa concepção não é unânime entre os consumidores, conforme pode ser observado no excerto: "O período de defeso não é importante porque o peixe fica muito caro" (Consumidor: 39, 73-M).

Novamente, observa-se que o problema apontado pelo sujeito da pesquisa não diz respeito ao período de defeso em si, mas a uma consequência da regulação do mercado, no que diz respeito à aplicação desta política pública.

A Figura 1 sistematiza as concepções acerca da importância deste evento para os atores sociais da

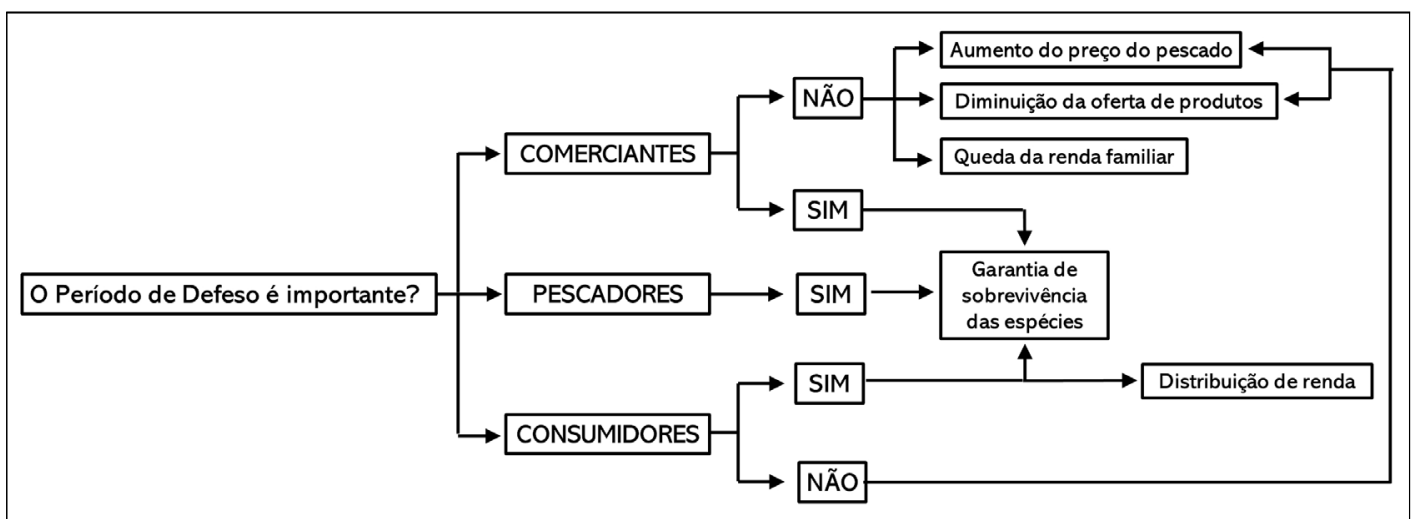

Figura 1 - Mapa conceitual elaborado a partir da sistematização das respostas dos atores sociais da Feira do Pescado da cidade de Santarém, Pará, acerca de questionamento quanto à importância do período de defeso. 
Feira do Pescado, em Santarém, Pará, evidenciando um mapa conceitual onde se pode observar, de forma compilada, os resultados encontrados.

\subsubsection{CATEGORIA 2: PROBLEMAS IDENTIFICADOS POR PESCADORES, CONSUMIDORES E COMERCIANTES}

No que tange à lei relacionada ao período de defeso, há diversos problemas elencados pelos sujeitos da pesquisa. Entre os pescadores entrevistados, os principais problemas apontados foram: desrespeito com o cumprimento da lei pelos próprios pescadores; ausência de órgãos oficiais para fiscalizar a prática da pesca e do comércio de espécies proibidas; indivíduos que recebem o seguro-defeso e não são pescadores; dificuldade dos pescadores artesanais em competir com os donos de geleiras ${ }^{1}$; atraso no pagamento do seguro-defeso; e equívoco quanto à data de fechamento da pesca para algumas espécies.

Alguns entrevistados afirmaram ser frequente a situação em que pescadores, mesmo quando beneficiados pelo seguro-defeso, continuam a realizar a pesca e a comercialização ilegal do pescado, ainda que corram o risco de ser multados pelos órgãos de fiscalização. Os trechos a seguir demonstram este panorama:

O problema é a continuidade da pesca, mesmo o pescador correndo o risco de ser multado pelos órgãos de fiscalização (Pescador: 1, 54-M).

[...] no mês de novembro ocorre a pesca indiscriminada com arrastões, praticada até mesmo por pescadores da região; a fiscalização é feita nos portos de Santarém, deixando os rios e os lagos descobertos aos invasores (Pescador: 6, 52-M).

O defeso é importante porque esse tempo que fica proibido serve para aumentar a população de peixe. Um dos problemas é pegar os peixes e comercializar mesmo sabendo que aquela espécie está proibida (Pescador: 15, 40-M).

Essa denúncia também aparece por parte dos comerciantes e dos consumidores entrevistados, segundo os quais muitos pescadores, apesar de receberem o seguro-defeso, ainda continuam pescando espécies proibidas:

Os maiores problemas são as pessoas que não respeitam a lei do pescado [...] (Comerciante: 56, 70-M).

O problema é que a maioria dos pescadores não cumpre a lei do defeso, mesmo recebendo o seguro (Comerciante: 64, 65-M)

O problema é que muitos pescadores não respeitam o período estabelecido pela lei e ainda recebem o seguro (Comerciante: 25, 52-M).

O problema é a falta de consciência das pessoas que não respeitam a lei; também falta fiscalização dos órgãos competentes nos rios da região (Comerciante: 32, 50-F).

Nesse sentido, tanto os pescadores quanto os comerciantes e os consumidores entrevistados

1 "Donos de geleiras" referem-se aos empresários proprietários de frigoríficos, os quais praticam a comercialização industrial do pescado. 
reivindicam maior fiscalização por parte dos órgãos competentes, de modo a coibir a prática da pesca no momento em que é proibida e aplicar sanções àqueles que não respeitam as leis. Para os três segmentos entrevistados, a fiscalização deve ir além dos portos de Santarém, necessitando atingir rios e lagos, que sempre ficam descobertos, com fácil acesso aos invasores:

Entre os maiores problemas está a pesca indiscriminada com arrastões no período de defeso; a falta de fiscalização tanto nos portos de Santarém quanto em locais mais distantes do município (Pescador: 10, 28-M)

[...] a fiscalização tem que agir no local da pescaria, porque depois que o peixe está morto não se pode jogar fora e a sua apreensão não é solução (Comerciante: 62, 43-M).

Um dos problemas é a captura dos peixes nessa época, necessitando de mais fiscalização nos lagos e menos nos portos de Santarém, porque depois dos peixes mortos não há mais nada o que fazer (Comerciante: 73, 29-F).

O problema é que os pescadores, em grande maioria, não cumprem a lei como deveriam. As pessoas têm que levar a sério, caso contrário não terá peixe no futuro; precisa de mais fiscalização pelo IBAMA (Consumidor: 23, 35-M).

Sendo assim, cabe discutir que, além de se criarem leis, são necessárias ações para que a legislação seja, de fato, colocada em prática. A Portaria do Defeso é de suma importância para permitir a perpetuação das espécies, no entanto, cabe ao governo fiscalizar o cumprimento dela pelos envolvidos. As denúncias dos pescadores e dos comerciantes da Feira do Pescado vão ao encontro de duas principais finalidades da política do seguro-defeso:

O primeiro [objetivo] é assegurar amparo ao pescador artesanal, sob a forma de transferência monetária, durante o período de defeso, quando ele não pode retirar sua subsistência do mar, dos rios ou dos lagos. O segundo objetivo, relacionado a este, é ajudar na preservação de várias espécies de peixes, crustáceos etc. cuja reprodução ocorre justamente durante o período de defeso (Campos \& Chaves 2014:77-78).

Sendo assim, zelar pelo cumprimento da legislação vigente é deveras relevante tanto para o pescador, apesar de muitos não terem ciência imediata dos benefícios desta política pública, quanto para as espécies de peixes mais comercializadas na região.

Outra denúncia feita pelos pescadores, comerciantes e consumidores entrevistados é de que há muitas pessoas que recebem o seguro-defeso sem fazer jus a ele, uma vez que não se tratam de pescadores. Mais uma vez, os entrevistados cobram um posicionamento dos órgãos fiscalizadores do Estado, que deveriam impedir o acontecimento de tais ações:

O benefício deveria atender apenas aos pescadores. Mas há outras pessoas que se beneficiam, recebendo o seguro, a exemplo de fazendeiros e comerciantes e, para coibir esse abuso deveria haver mais fiscalização 
por parte do governo (Pescador: 4, 32-M).

Os maiores problemas do defeso são as pessoas que não respeitam as leis, pois continuam pescando as espécies proibidas; falta mais fiscalização por parte dos órgãos responsáveis; muitas pessoas também continuam recebendo o seguro sem ser pescador (Pescador: $8,45-\mathrm{M})$.

O problema é que os comerciantes não recebem o seguro, mas há pessoas que recebem e não trabalham com peixe (Comerciante: 78, 51-M).

Um dos problemas é que muitos pescadores não podem pescar; há pescadores que não recebem o seguro e outros que nem são pescadores recebem (Consumidor: 22, 28-M).

Note-se que, na denúncia do consumidor (22, 28-M), há a informação de que muitos pescadores acabam por não receber o seguro-defeso, o que frequentemente faz com que o indivíduo descumpra a legislação vigente para que possa manter a subsistência própria e de seus familiares. Essa denúncia aparece na fala de muitos pescadores entrevistados, que se ressentem da demora da liberação do benefício. Não é raro o período chegar ao seu término e muitos não terem recebido o recurso. Assim, por necessidade, são obrigados a pescar, mesmo sabendo que as espécies estão proibidas.

Um dos maiores problemas é quando o seguro não é liberado no período certo e os pescadores são obrigados a pescar, mesmo sabendo que aquela espécie está proibida. Sem a regulamentação, a captura dos peixes ficaria cada vez mais difícil (Pescador: 9, 46-M).

Fica clara, na fala dos entrevistados, a necessidade de que as políticas públicas em relação ao período de defeso sejam mais eficientes, tanto no que tange à fiscalização, impedindo que haja a pesca no período de reprodução das espécies, quanto na celeridade do pagamento do benefício, de modo a permitir a subsistência dos pescadores e de suas famílias, sem que sejam levados a cometer atividades ilícitas.

Soma-se a tantos problemas a denúncia feita por pescadores sobre a realização de contrabando do pescado, praticado por comerciantes que são donos de grandes geleiras e vêm de outros estados para comercializar peixes de maneira desleal, levando o produto para a capital do Pará e do Amapá, enquanto os pescadores artesanais são proibidos de praticar esse comércio: "Um dos problemas do defeso é que os donos de geleiras fazem a comercialização desleal, levando o pescado para a capital do estado, enquanto que os pescadores artesanais são proibidos de pescar" (Pescador: 5, 57-M).

A última problemática apontada pelos pescadores entrevistados foi a data equivocada do período de defeso para algumas espécies:

[...] a data do período de defeso deveria ser prolongada, pois termina quando muitas espécies ainda estão desovando (Pescador: 7, 40-M).

[...] a data em relação a algumas espécies está errada, a exemplo do curimatá, aracu, mapará e pirarucu, pois quando termina o 
defeso, essas e outras espécies ainda estão desovando (Pescador: 14, 49-M).

Ou seja, segundo os pescadores entrevistados, no momento de encerramento do defeso, isto é, quando a pesca é novamente liberada, muitas espécies encontram-se em período de reprodução. Assim, o maior objetivo desta política pública (permitir que as populações de peixes se recuperassem) não está sendo exitoso. Esta denúncia também aparece nas falas dos comerciantes, que corroboram a problemática apontada pelos pescadores: "a data está errada, pois dependendo da chuva, muitas espécies ainda estão desovando quando o defeso termina, a exemplo do aracu, curimatá e pacu desovando" (Comerciante: 56, 70-M).

Os comerciantes e os consumidores entrevistados também denunciam que, com o período de defeso, há escassez de pescado disponível para venda, o que culmina na elevação dos preços. Desse modo, as vendas diminuem drasticamente, o que leva a uma queda na renda familiar do comerciante e compele a uma mudança nos hábitos alimentares da população local.

Os maiores problemas é que a gente fica sem poder vender o peixe proibido; diminui a oferta do pescado e por isso fica mais caro (Comerciante: 55, 54-F).

O problema é que a maioria dos pescadores não cumpre a lei do defeso, mesmo recebendo o seguro; por outro lado, a nossa venda cai muito nessa época já que não podemos comercializar as espécies proibidas e não recebemos o seguro, assim como os pescadores (Comerciante: 64, 65-M).
Um dos problemas é que não podemos comercializar as espécies proibidas, mas as pessoas procuram muito; deveríamos receber o seguro assim como os pescadores para suprir nossos prejuízos (Comerciante: 76, 26-M).

O maior problema é a falta de respeito de muitas pessoas que não cumprem a lei; nesse período falta peixe nas feiras e mercados, com isso aumenta consideravelmente o preço (Consumidor: 34, 40-F).

A maioria dos comerciantes reivindica o recebimento do seguro, assim como os pescadores o recebem. Apesar de poder comercializar pescado de cativeiro, os comerciantes alegam que esta categoria de peixes apresenta custos mais elevados do que a pesca extrativista, o que faz com que as vendas diminuam.

Essa é uma discussão que não pode ser ignorada quando pensamos na implementação de ações de preservação ambiental. De um lado, tem-se o ambiente, que precisa ser protegido para garantir a manutenção das espécies; do outro, a sobrevivência de famílias, que dependem da comercialização de espécies para subsistirem. Percebe-se, portanto, a complexidade desta discussão, que demanda intensos debates, entre os mais diversos atores sociais envolvidos neste processo.

A Figura 2 sistematiza os problemas identificados por pescadores, consumidores e comerciantes da Feira do Pescado, em Santarém, Pará, trazendo um mapa conceitual, no qual se pode observar, de forma compilada, os resultados encontrados. 


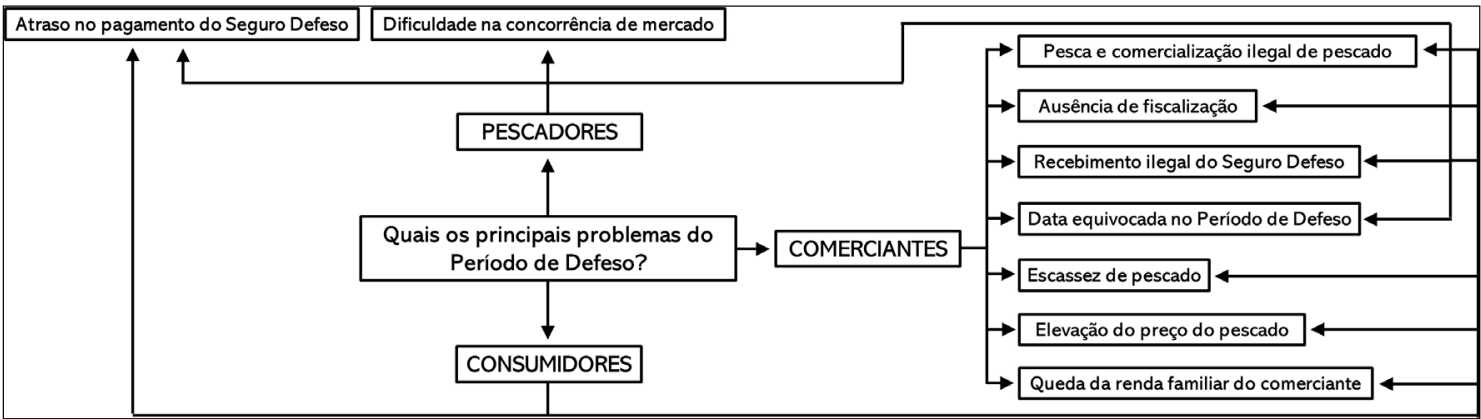

Figura 2 - Mapa conceitual elaborado a partir da sistematização das respostas dos atores sociais da Feira do Pescado, na cidade de Santarém, Pará, acerca do questionamento sobre quais são os principais problemas identificados quanto ao período de defeso.

\section{CONCLUSÕES}

Este artigo investigou, de forma sucinta, as perspectivas dos principais atores sociais que trabalham com a pesca e a comercialização na Feira do Pescado, em Santarém, Pará, assim como alguns aspectos do seguro-defeso.

Pelas perspectivas dos pescadores, comerciantes e consumidores, observa-se que a pesca artesanal em Santarém, Pará, enfrenta desafios diversos nas áreas social, econômica e ambiental, de modo a atender à demanda crescente da comunidade, ao mesmo tempo em que há uma inegável necessidade de ações visando à preservação ambiental das espécies de pescado. Muitas das problemáticas levantadas tornam-se ainda mais acentuadas pela falta de fiscalização eficiente, que seja capaz de coibir a pesca indiscriminada, em contínua ascendência.

É válido destacar que, durante os trabalhos de campo, notamos a completa ausência de algum tipo de controle ou fiscalização no local por parte do Instituto Brasileiro do Meio Ambiente e dos Recursos Naturais Renováveis (IBAMA), da Divisão de Vigilância Sanitária (DIVISA) e da Secretaria Municipal de Meio Ambiente (SEMMA). Além disso, a organização mínima que há no espaço parte sempre do interesse dos próprios atores sociais que atuam na Feira do Pescado. Desse modo, apesar de a pesca ser uma das atividades econômicas e sociais mais importantes da Amazônia, em especial em Santarém, percebe-se o descaso do poder público com a atividade.

Constatamos que muitos dos entrevistados conhecem e até defendem a existência de um período de fechamento da pesca, no entanto continuam praticando o comércio ilicitamente. Este dado indica que, muitas vezes, apenas o conhecimento não é suficiente para que haja mudança efetiva de comportamento, dado que as necessidades reais de subsistência do indivíduo e de sua família acabam por ser priorizadas.

A pesquisa ainda deixa claro que o desconhecimento acerca da biologia e da fisiologia das espécies tende a perpetuar a falsa concepção de que os recursos naturais são infinitos. Assim, muitos indivíduos que compartilham destas ideias argumentam que legislações para a proteção da desova das espécies e o crescimento dos alevinos são desnecessários.

Nesse sentido, apresentamos algumas sugestões de ações que podem contribuir para reduzir os problemas identificados, de ordem 
legal, social, econômica e ambiental, dado que estes, uma vez reduzidos ou sanados, podem ajudar no processo de elaboração de políticas públicas mais eficientes à pesca artesanal em Santarém e região, a saber: implementar ações mais eficientes de controle, monitoramento e fiscalização da produção pesqueira, assim como armazenamento e escoamento da produção; dinamizar a cadeia produtiva de pescado, de forma a garantir o aumento da regularidade da oferta, da qualidade e da renda dos pescadores; fortalecer acordos de cooperação técnica entre Estado, município e outras entidades afins com a atividade pesqueira, com vistas a proporcionar melhores condições aos pescadores, comerciantes e consumidores; criar estímulos e colaboração para que ações de proteção dos recursos naturais de várzeas sejam empreendidas pelos próprios membros da comunidade; adotar pedagogia mais acessível para divulgar as informações técnico-científicas junto às comunidades, visando fortalecer o entendimento dos comunitários sobre a preservação das espécies; romper o isolamento existente entre os segmentos sociais dos pescadores e das instituições públicas nos diversos setores, visando à troca de conhecimentos e experiências; implementar ações que possibilitem que os veículos de comunicação divulguem informações e serviços a serem prestados aos pescadores, comerciantes e consumidores.

Embora se trate de uma pesquisa inicial, este estudo, sem jamais ousar concluir a discussão, tem a finalidade primeira de ampliar e provocar o debate sobre a temática, fazendo com que novos desafios sejam envidados, em busca de aprofundar cada vez mais a pesquisa sobre um dos setores mais importantes que move a economia, a cultura e o meio ambiente em Santarém e região.

\section{REFERÊNCIAS}

Bardin, L. 1977. Análise de conteúdo. Tradução de L. A. Reto e A. Pinheiro. Lisboa: Edições 70.

Brasil. 2003. Lei n ${ }^{\circ}$ 10.779, de 25 de novembro de 2003. Dispõe sobre a concessão do benefício de seguro desemprego, durante o período de defeso, ao pescador profissional que exerce a atividade pesqueira de forma artesanal. Diário Oficial da União, 26 nov. 2003.

Campos, A. G., e J. V. Chaves. 2014. Seguro defeso: problemas enfrentados pelo programa. Mercado de Trabalho (56):77-84.

Castro, F., e D. Mcgrath. 2001. O manejo comunitário de lagos na Amazônia. Parcerias Estratégicas 6(12):112-126.

Cerdeira, R. G. P., M. L. Ruffino, e V. J. Isaac. 1997. Consumo de pescado e outros alimentos pela população ribeirinha do Lago Grande de Monte Alegre, PA - Brasil. Acta Amazonica 27(3):213-228. DOI: http://dx.doi.org/10.1590/180943921997273228 .

Ferreira, R. R., e R. E. Silva. 2017. Acordo de pesca como gestão dos recursos: o caso da Ilha de São Miguel, Santarém, Pará. Amazônica: Revista de Antropologia 9(1):156-178. DOI: http://dx.doi. org/10.18542/amazonica.v9i1.5487.

Gil, A. C. 1999. Métodos e técnicas de pesquisa social. São Paulo: Atlas. 
Grácio, M. M. C., e E. A. Garrutti. 2005. Estatística aplicada à educação: uma análise de conteúdos programáticos de planos de ensino de livros didáticos. Revista de Matemática e Estatística 23(3):107-126.

Instituto Brasileiro de Geografia e Estatística (IBGE). 2017. Disponível em: https://www.ibge. gov.br. Acesso em: 16 dez. 2017.

Instituto Brasileiro do Meio Ambiente e dos Recursos Naturais Renováveis (IBAMA). 2002. Projeto Manejo dos Recursos Naturais da Várzea - ProVárzea: conceito e estratégia. 1. ed. Manaus: IBAMA/ProVárzea.

Instituto Brasileiro do Meio Ambiente e dos Recursos Naturais Renováveis (IBAMA). 2004. Instrução Normativa n 34, 18 de junho de 2004. Diário Oficial da União, 22 jun. 2004.

Instituto Brasileiro do Meio Ambiente e dos Recursos Naturais Renováveis (IBAMA). 2005. Instrução Normativa $n^{\circ} 35,29$ de setembro de 2005. Diário Oficial da União, 30 set. 2005.

Instituto Brasileiro do Meio Ambiente e dos Recursos Naturais Renováveis (IBAMA). 2007. Instrução Normativa ${ }^{\circ}$ 48, 05 de novembro de 2007. Diário Oficial da União, 6 nov. 2007.

Instituto Brasileiro do Meio Ambiente e dos Recursos Naturais Renováveis (IBAMA). 2014. Lei da vida: Lei dos crimes ambientais: Lei $n^{\circ} 9.605$, de 12 de fevereiro de 1998 e Decreto $n^{\circ}$ 6.514, de 22 de julho de 2008. 2. ed., revista e atualizada. CNIA. Brasília: IBAMA.

Kauark, F. S., F. C. Manhães, e C. H. Medeiros. 2010. Metodologia da pesquisa: um guia prático. Itabuna: Via Litterarum.

Lüdke, M., e M. E. D. A. André. 1986. Pesquisa em educação: abordagens qualitativas. 6. ed. São Paulo: EPU.

Maia, M. B. R. 2009. Do defeso ao seguro desemprego do pescador artesanal: a inclusão do pescador nas políticas públicas de seguridade social. Dissertação de Mestrado, Departamento de Sociologia, Universidade Federal do Amazonas, Manaus.

Mathis, A. 2001. Reflexões sobre a reforma do Estado na Amazônia, in Estado e políticas públicas na Amazônia: gestão do desenvolvimento regional. Organizado por M. C. N. Coelho et al., pp. 85-90. Belém: Cejup/UFPA-NAEA.

Moreira, H. C. L., E. F. Scherer, e S. M. Sales. 2009. A política do eco defeso e os pescadores artesanais da comunidade do Cai na Água - Manaquiri/AM. Reunião Anual da Sociedade Brasileira para o Progresso da Ciência 61.

Peres, J. A. A., P. R. Pezzuto, L. F. Rodrigues, H. Valentini, e C. M. Vooren. 2001. Relatório da reunião técnica de ordenamento da pesca de arrasto nas regiões Sudeste e Sul do Brasil. Notas Técnicas Facimar 5:1-34. 
Pieve, S. M. N., S. G. Coelho, e R. R. Kubo. 2008. Conflitos socioambientais: o papel da legislação ambiental na utilização de recursos naturais. Encontro da Rede de Estudos Rurais 3:1-15.

Santos, M. T. 2005. Aprendizados do Projeto Manejo dos Recursos Naturais da Várzea - ProVárzea. Brasília: Ministério do Meio Ambiente.

Silva, R. E., e R. R. Ferreira. 2018. Construção de acordos de pesca e políticas públicas para gestão de recursos pesqueiros na região de Santarém, Pará (1990-2004). O Social em Questão 21(41):327-354.

Silva-Forsberg, M. C., M. B. Raseira, e E. P. L. Câmara. 2006. Encontros e desencontros na elaboração e na implementação de um sistema de monitoramento e avaliação de impactos: as lições do ProVárzea/IBAMA, in Estratégias e métodos de monitoramento em projetos de proteção das florestas tropicais brasileiras. Organizado por R. Guerra \& P. Ascher, pp. 85-116. Brasília: MMA.

Stake, R. E. 1983. Pesquisa qualitativa/naturalista: problemas epistemológicos. Educação e Seleção(7):19-27.

Teixeira, E. 2006. As três metodologias: acadêmica, da ciência e da pesquisa. 2. ed. Petrópolis, RJ: Vozes.

Vasques, R. O., e E. C. G. Couto. 2011. Percepção dos pescadores quanto ao estabelecimento do período de defeso da pesca de arrasto para a região de Ilhéus (Bahia, Brasil). Revista da Gestão Costeira Integrada 11(4):479-485.

Vidal, M. D., M. B. Raseira, e M. L. Ruffino. 2015. Manejo participativo dos recursos naturais amazônicos - a experiência do ProVárzea. Biota Amazônia 5(1):53-60. DOI: http://dx.doi. org/10.18561/2179-5746/biotaamazonia.v5n1p53-60. 
APÊNDICE 1 - Questionário aplicado aos 80 participantes da pesquisa, sendo 20 pescadores, 30 comerciantes e 30 consumidores.

\section{QUESTIONÁRIO}

LOCAL: Feira do Pescado

NÚMERO DA FONTE PESQUISADA:

ESCOLARDADE:

\section{CATEGORIA:}

IDADE:

GÊNERO ( )

1. Você e favorável ao Período do Defeso?

$\operatorname{SIM}(\quad) \quad \mathrm{NÃO}($ )

2. Você tem conhecimento sobre o Período do Defeso?

$\operatorname{SIM}(\quad) \quad \mathrm{NÃO}(\quad)$

3. Pescadores e vendedores: você comercializa ou já comercializou pescado no Período do Defeso? (Aos consumidores: Você consome ou já consumiu pescado proibido no Período do Defeso?)

$\operatorname{SIM}(\quad) \quad \mathrm{NÃO}(\quad)$

4. Para você, ainda haveria peixe em abundância sem o Período do Defeso?

$\operatorname{SIM}(\quad) \quad \mathrm{NATO}($ )

5. O Período do Defeso é importante?

$\operatorname{SIM}(\quad) \quad \mathrm{NÃO}(\quad)$

Por que?

6. Na sua opinião, quais os principais problemas sobre o Período do Defeso?

7. Na sua opinião, o que aconteceria se não houvesse período do defeso?

Agradecemos a sua participação neste projeto de investigação. Se tiver alguma questão ou observação a este questionário, utilize o espaço abaixo. 